\title{
Comparison of clinical outcomes in decompression and fusion versus decompression only in patients with ossification of the posterior longitudinal ligament: a meta-analysis
}

\author{
Syed K. Mehdi, BS, ${ }^{2}$ Vincent J. Alentado, BS, ${ }^{2}$ Bryan S. Lee, MD, ${ }^{3}$ Thomas E. Mroz, MD, ${ }^{1}$ \\ Edward C. Benzel, MD, ${ }^{1,3}$ and Michael P. Steinmetz, MD ${ }^{1,3}$ \\ ${ }^{1}$ Center for Spine Health and ${ }^{3}$ Department of Neurological Surgery, Cleveland Clinic; and ${ }^{2}$ Case Western Reserve University \\ School of Medicine, Cleveland, Ohio
}

OBJECTIVE Ossification of the posterior longitudinal ligament (OPLL) is a pathological calcification or ossification of the PLL, predominantly occurring in the cervical spine. Although surgery is often necessary for patients with symptomatic neurological deterioration, there remains controversy with regard to the optimal surgical treatment. In this systematic review and meta-analysis, the authors identified differences in complications and outcomes after anterior or posterior decompression and fusion versus after decompression alone for the treatment of cervical myelopathy due to OPLL.

METHODS A MEDLINE, SCOPUS, and Web of Science search was performed for studies reporting complications and outcomes after decompression and fusion or after decompression alone for patients with OPLL. A meta-analysis was performed to calculate effect summary mean values, $95 \% \mathrm{Cls}, \mathrm{Q}$ statistics, and $\mathrm{I}^{2}$ values. Forest plots were constructed for each analysis group.

RESULTS Of the 2630 retrieved articles, 32 met the inclusion criteria. There was no statistically significant difference in the incidence of excellent and good outcomes and of fair and poor outcomes between the decompression and fusion and the decompression-only cohorts. However, the decompression and fusion cohort had a statistically significantly higher recovery rate $(63.2 \%$ vs $53.9 \%$; $p$ <.0001), a higher final Japanese Orthopaedic Association score (14.0 vs 13.5; $p<0.0001$ ), and a lower incidence of OPLL progression (< $1 \%$ vs $6.3 \% ; p<0.0001$ ) compared with the decompressiononly cohort. There was no statistically significant difference in the incidence of complications between the 2 cohorts.

CONCLUSIONS This study represents the only comprehensive review of outcomes and complications after decompression and fusion or after decompression alone for OPLL across a heterogeneous group of surgeons and patients. Based on these results, decompression and fusion is a superior surgical technique compared with posterior decompression alone in patients with OPLL. These results indicate that surgical decompression and fusion lead to a faster recovery, improved postoperative neurological functioning, and a lower incidence of OPLL progression compared with posterior decompression only. Furthermore, decompression and fusion did not lead to a greater incidence of complications compared with posterior decompression only.

http://thejns.org/doi/abs/10.3171/2016.3.FOCUS1630

KEY WORDS fusion; decompression; cervical myelopathy; OPLL progression; outcomes; ossification of the posterior longitudinal ligament; complications

$\mathrm{O}$ SSIFICATION of the posterior longitudinal ligament (OPLL) is a pathological calcification or ossification of the PLL that plays a major role in preventing hyperflexion. This calcification can narrow the spinal canal, leading to spinal cord compression and neurological complications.$^{35}$ OPLL was first described in the Japanese and East Asian populations, where it is a common cause of cervical myelopathy. ${ }^{54}$ In Japan, the incidence of OPLL has been estimated at $1.9 \%-4.3 \%$ in patients with cervical spine disorders. ${ }^{32}$ In other Asian countries, that inci-

ABBREVIATIONS ADF = anterior decompression and fusion; JOA = Japanese Orthopaedic Association; MCID = minimal clinically important difference; OPLL = ossification of the posterior longitudinal ligament; PDF = posterior decompression and fusion; PRO = patient-reported outcome. 
dence is as high as $3.0 \% .^{33}$ Recent research, however, has shown that OPLL has an incidence of $0.1 \%-1.7 \%$ among North Americans and Europeans with cervical spine disorders. ${ }^{13,37}$ The increasing awareness of OPLL requires surgeons to be familiar with all viable treatment options.

Although surgery is often necessary for patients with symptomatic neurological deterioration caused by OPLL, there remains controversy with regard to the optimal surgical treatment. Surgical decompression and stabilization via cervical fusion is widely accepted as the optimal treatment for patients with cervical radiculopathy or myelopathy caused by OPLL. ${ }^{21,34}$ Although anterior decompression and fusion (ADF) is associated with better maintenance of cervical lordosis, ${ }^{38,48}$ it is also associated with higher rates of dysphagia and dural tears. ${ }^{39}$ It is also a more technically difficult procedure than a decompression alone. A major disadvantage of posterior decompression without fusion is an inability to correct cervical kyphosis..$^{19}$ Both approaches, however, can lead to progression of OPLL postoperatively. ${ }^{17,24}$ Some surgeons hypothesize that decompression and fusion may slow the progression of OPLL, but there is limited evidence to support this hypothesis. ${ }^{45}$

Comparison of the rate of progression of an OPLL mass and patient outcomes after ADF or posterior decompression and fusion (PDF) versus decompression without fusion (laminectomy and laminoplasty) is necessary for surgeons to provide the best care possible for their patients. To date, several studies have compared outcomes of ADF or PDF versus decompression alone in patients with OPLL and associated cervical myelopathy, with a variety of outcomes measures and results. $6,7,14,16,20,25,32,44,48,59$ In the current study, we provide a systematic review of the literature and a meta-analysis of patient outcomes following either ADF or PDF surgery or posterior decompression alone (inclusive of laminectomy and laminoplasty) for OPLL causing cervical myelopathy, to better define outcomes after each procedure. In doing so, we hope to better educate patients and surgeons and to help guide the surgical decision-making process.

\section{Methods}

\section{Study Search}

A MEDLINE, SCOPUS, and Web of Science database search was performed with the following search algorithm: ossification of posterior longitudinal ligament OR OPLL AND (cervical AND (spine OR surgery OR myelopathy OR fusion)). The search returned 2630 citations. The search period ended November 20, 2015.

\section{Inclusion and Exclusion Criteria}

Clinical studies focusing on outcomes of cervical spine decompression and fusion or decompression alone for patients with OPLL causing cervical myelopathy were included in this study. Studies with procedures crossing the cervicothoracic spine were excluded to minimize the potentially confounding effects of the complex biomechanics of this region. Case studies and review articles along with animal, in vitro, biomechanical, and non-English studies were also excluded. Due to the limited amount of published data, both retrospective and prospective studies were included.
Studies in the "decompression and fusion" category contained patients who underwent ADF or PDF. Studies in the "decompression only" category contained patients who underwent laminoplasty or laminectomy without fusion.

\section{Data Collection}

The initial 2630 citations were reviewed. After 1151 duplicates were removed, the titles and abstracts of 1479 citations were screened. At this stage, studies that did not mention OPLL, surgical procedures, patient outcomes, or postoperative complications; that did not contain Japanese Orthopaedic Association (JOA) scoring; or that did not fulfill the inclusion criteria were excluded. Based on these criteria, 1378 citations were excluded. Full texts of the remaining 101 articles were assessed for inclusion eligibility.

Full-text assessment resulted in 32 eligible articles included in the final analysis (Fig. 1). ${ }^{41}$ One reviewer (S.K.M.) independently conducted data extraction from the 32 included articles. Bias risk assessment was not performed in this review because most studies were retrospective in design, thereby expressing strong inherent bias. From the eligible articles, the following information was obtained: publication year, study design, sample size, patient age, OPLL occupying ratio percentage (defined as the percentage of the spinal canal that is occupied by the OPLL mass), preoperative JOA score, postoperative JOA score, mean follow-up time (in years), recovery rate percentage, complication rate, and surgical reoperation rate (Tables 1 and 2). Studies that used the Hirabayashi method to define postoperative patient outcome as excellent, good, fair, and poor were used for the meta-analysis. These outcomes were based on the recovery rate (\%) and were calculated as follows: ${ }^{25}$ (Postoperative JOA score - Preoperative JOA score $) /(17$ - Preoperative JOA score $) \times 100$.

The highest attainable JOA score is 17 . A recovery rate $>75 \%$ is considered an excellent outcome, a recovery rate of $50 \%-75 \%$ is considered a good outcome, a recovery rate of $25 \%-49 \%$ is considered a fair outcome, and a recovery rate $<25 \%$ is considered a poor outcome. ${ }^{21}$

\section{Statistical Analysis}

A meta-analysis of the 32 included studies was performed. A random-effects model with inverse variance weighting was used to analyze the data. All calculations for the meta-analysis, as well as any construction of forest plots, were accomplished using a previously published spreadsheet by Neyeloff et al. ${ }^{42}$ The principal summary measure consisted of the effect summary mean and the 95\% CIs. Due to the lack of control groups in the 32 included studies, there was no calculation of relative risk ratios. The 95\% CIs and forest plots were the primary tools for comparisons among studies.

Meta-analysis calculations and constructed forest plots were completed in 6 different categories for the included studies. These categories consisted of number of excellent and good outcomes, number of fair and poor outcomes, and complications in decompression and fusion and in decompression-only operations. To allow for the inclusion of studies that did not contain any complications, a value of 0.1 event per study was used for calculations. To assess 


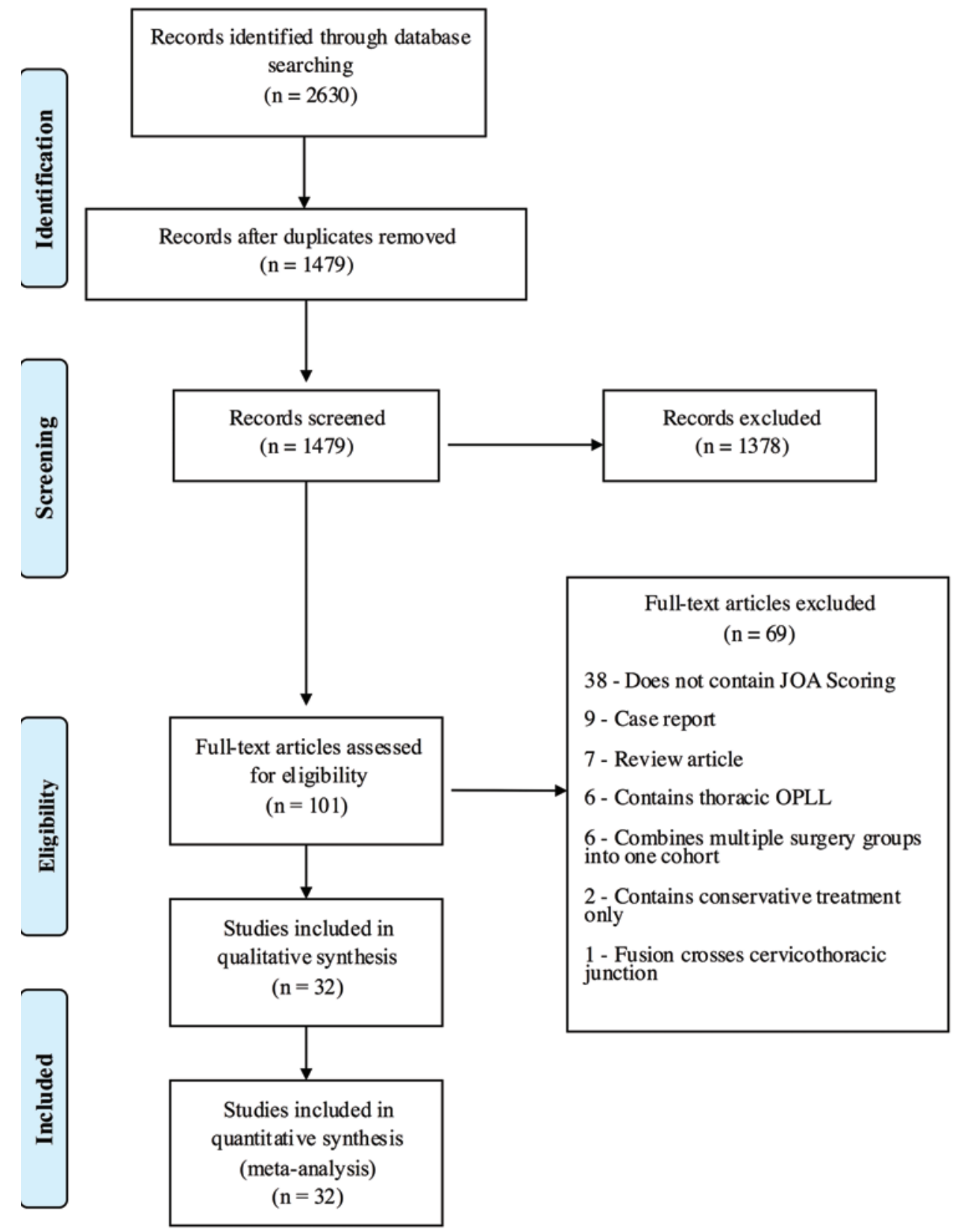

FIG. 1. The Preferred Reporting Items for Systematic Reviews and Meta-Analyses (PRISMA) flow diagram for selection of studies based on inclusion criteria during systematic review.

heterogeneity between individual studies, a Q and an $\mathrm{I}^{2}$ value were calculated within the 2 meta-analysis groups. The $\mathrm{I}^{2}$ calculates the distribution across effect sizes and represents the percentage of observed interstudy variance that is a result of true differences in effect sizes. ${ }^{12}$ According to DeLong et al., an $\mathrm{I}^{2}$ value $<25 \%$ has low heterogeneity, an $\mathrm{I}^{2}$ value of $25 \%-75 \%$ has moderate heterogeneity, and an $\mathrm{I}^{2}$ value $>75 \%$ has severe heterogeneity. ${ }^{12}$

\section{Results}

\section{Study Characteristics}

Of the 32 studies included in this review, 3 were pro- spective cohort studies, 1 was a prospective comparative clinical study, 1 was a retrospective clinical study, 1 was a case series, and 26 were retrospective cohort studies. The year of publication ranged from 1994 to 2015. The study sizes for patients who received ADF or PDF ranged from 12 to 133 , whereas the study sizes for patients who received decompression only ranged from 15 to 82 . There were 10 studies that contained both decompression and fusion and decompression-only patient populations. . $^{2,67,14,16,20,23,25,48,59}$ Three studies in the fusion category contained patient populations that underwent either ADF or PDF. ${ }^{6,7,31}$ The total sample size for patients who received ADF or PDF or who received decompression only was 1222 and 745, 
TABLE 1. Characteristics of 24 included studies that contained patients who underwent decompression and fusion

\begin{tabular}{|c|c|c|c|c|}
\hline Authors \& Year & $\begin{array}{l}\text { Op } \\
\text { Type }\end{array}$ & Study Type & $\begin{array}{c}\text { Sample } \\
\text { Size }\end{array}$ & $\begin{array}{c}\text { Mean Age, } \\
\text { Yrs }\end{array}$ \\
\hline Masaki et al., 2007 & ADF & Prospective & 19 & 51.8 \\
\hline Fujimori et al., 2014 & ADF & Retrospective & 12 & 55.6 \\
\hline Sakai et al., 2012 & $A D F$ & $\begin{array}{l}\text { Prospective } \\
\text { comparative }\end{array}$ & 20 & 59.5 \\
\hline Iwasaki et al., 2007 & ADF & Retrospective & 27 & 58.0 \\
\hline Kim et al., 2015 & $A D F$ & $\begin{array}{r}\text { Retrospective } \\
\text { case study }\end{array}$ & 71 & 57.3 \\
\hline Chen et al., $2009^{4}$ & ADF & Prospective & 19 & 57.2 \\
\hline Lei et al., 2014 & ADF & Retrospective & 22 & 58.0 \\
\hline Wang et al., 2012 & ADF & Case series & 29 & 59.3 \\
\hline Mochizuki et al., 2009 & ADF & Retrospective & 20 & 59.4 \\
\hline Qizhi et al., 2012 & ADF & Retrospective & 23 & 58.4 \\
\hline Chen et al., 2014 & ADF & Retrospective & 133 & 56.8 \\
\hline Lin et al., 2012 & ADF & Retrospective & 26 & 54.7 \\
\hline Lin et al., 2012 & PDF & Retrospective & 30 & 56.2 \\
\hline Chen et al., $2009^{5}$ & PDF & Retrospective & 83 & 56.4 \\
\hline Chen et al., 2011 & ADF & Retrospective & 22 & 57.2 \\
\hline Chen et al., 2011 & PDF & Retrospective & 28 & 55.3 \\
\hline Kim et al., 2009 & ADF & Retrospective & 17 & 57.5 \\
\hline Yuan et al., 2015 & PDF & Prospective & 18 & 62.0 \\
\hline Chen et al., 2012 & ADF & Retrospective & 91 & 48.7 \\
\hline Chen et al., 2012 & PDF & Retrospective & 32 & 52.6 \\
\hline Katsumi et al., 2015 & PDF & Retrospective & 19 & 61.0 \\
\hline Yamaura et al., 1999 & ADF & Retrospective & 107 & 57.0 \\
\hline Matsuoka et al., 2001 & ADF & Retrospective & 63 & 57.0 \\
\hline Goto \& Kita, 1995 & ADF & Retrospective & 50 & 54.4 \\
\hline Odate et al., 2012 & ADF & Retrospective & 68 & 58.0 \\
\hline Baba et al., 1995 & ADF & Retrospective & 88 & 47.0 \\
\hline Baba et al., 1994 & ADF & Retrospective & 85 & 49.0 \\
\hline Total & & & 1222 & 55.0 \\
\hline
\end{tabular}

respectively. Postoperative outcomes for patients who underwent decompression and fusion were identified in 12 studies $^{4-6,14,16,20,25,31,32,36,46,56}$ and in 7 studies for patients who underwent posterior decompression only. ${ }^{2,6,10,14,20,25,32}$ Two of the studies in the fusion category contained both $\mathrm{ADF}$ and PDF patient groups.

\section{Excellent and Good Outcomes in Patients Who Underwent Decompression and Fusion Versus Posterior Decompression Only}

For the decompression and fusion population, the overall prevalence of excellent and good outcomes was 71.1\% (95\% CI 63.9\%-78.2\%). An analysis of the studies indicated no heterogeneity, with an $\mathrm{I}^{2}$ value of $0 \%$ (Fig. 2). For posterior decompression only, the overall prevalence of excellent and good outcomes was $54.0 \%$ (95\% CI 38.6\%$69.3 \%)$. An analysis of the studies indicated that a moderate heterogeneity existed, with an $\mathrm{I}^{2}$ value of $66 \%$ (Fig. 3). Given the overlapping 95\% CIs, there was no statistically
TABLE 2. Characteristics of 14 included studies that contained patients who underwent decompression only

\begin{tabular}{lclcc}
\hline \multicolumn{1}{c}{ Authors \& Year } & $\begin{array}{c}\text { Op } \\
\text { Type }\end{array}$ & Study Type & $\begin{array}{c}\text { Sample } \\
\text { Size }\end{array}$ & $\begin{array}{c}\text { Mean } \\
\text { Age, Yrs }\end{array}$ \\
\hline Masaki et al., 2007 & LP & Retrospective & 40 & 62.6 \\
\hline Fujimori et al., 2014 & LP & Retrospective & 15 & 58.7 \\
\hline Sakai et al., 2012 & LP & $\begin{array}{c}\text { Prospective } \\
\text { comparative }\end{array}$ & 22 & 58.4 \\
\hline Iwasaki et al., 2007 & LP & Retrospective & 66 & 57.0 \\
\hline Kim et al., 2015 & LP & Retrospective & 64 & 56.4 \\
\hline Chen et al., 2011 & LP & Retrospective & 25 & 54.2 \\
\hline Yuan et al., 2015 & LP & Prospective & 20 & 59.0 \\
\hline Chen et al., 2012 & LP & Retrospective & 41 & 46.3 \\
\hline Katsumi et al., 2015 & LP & Retrospective & 22 & 59.0 \\
\hline Ogawa et al., 2004 & LP & Retrospective & 72 & 57.9 \\
\hline Baba et al., 1995 & LP & Retrospective & 47 & 56.0 \\
\hline Yang et al., 2007 & LP & Retrospective & 27 & 61.0 \\
\hline Kawaguchi et al., 2001 & LP & Retrospective & 45 & 55.2 \\
\hline Goto \& Kita, 1995 & LP & Retrospective & 65 & 58.2 \\
\hline Cho et al., 2008 & LA & Retrospective & 14 & 57.0 \\
\hline Lee et al., 2016 & LA & Retrospective & 34 & 57.8 \\
\hline Kato et al., 1998 & LA & Retrospective & 44 & 57.0 \\
\hline Zhao et al., 2012 & LA & Retrospective & 82 & 57.6 \\
\hline Total & & & 745 & 57.0 \\
\hline LA 2 (am. & & & \\
\hline
\end{tabular}

$\mathrm{LA}=$ laminectomy; $\mathrm{LP}=$ laminoplasty.

significant difference of excellent and good outcomes between the 2 cohorts.

\section{Fair and Poor Outcomes in Patients Who Underwent Decompression and Fusion Versus Posterior Decompression Only}

For the decompression and fusion population, the overall prevalence of fair and poor outcomes was $24.8 \%$ (95\% CI $18.3 \%-31.3 \%)$. An analysis of the studies indicated a moderate heterogeneity, with an $\mathrm{I}^{2}$ value of $59 \%$ (Fig. 4). For posterior decompression only, the overall prevalence of fair and poor outcomes was 37.8\% (95\% CI 27.3\%48.2\%). An analysis of the studies indicated a moderate heterogeneity, with an $\mathrm{I}^{2}$ value of $45 \%$ (Fig. 5). There was no statistically significant difference of fair and poor outcomes between cohorts.

\section{Postoperative Neurological Outcomes in Patients Who Underwent Decompression and Fusion Versus Posterior Decompression Only}

The JOA score was used to determine pre- and postoperative neurological outcomes in patients who underwent decompression and fusion or posterior decompression only. These scores were present in each of the 32 included studies. The fusion patient population demonstrated a preoperative JOA score similar to the decompression patient population (9.4 vs 9.2, respectively; $\mathrm{p}=0.07$ ). However, the fusion cohort demonstrated a statistically significantly higher final JOA score (14.0 vs 13.5; p < 0.0001) and re- 


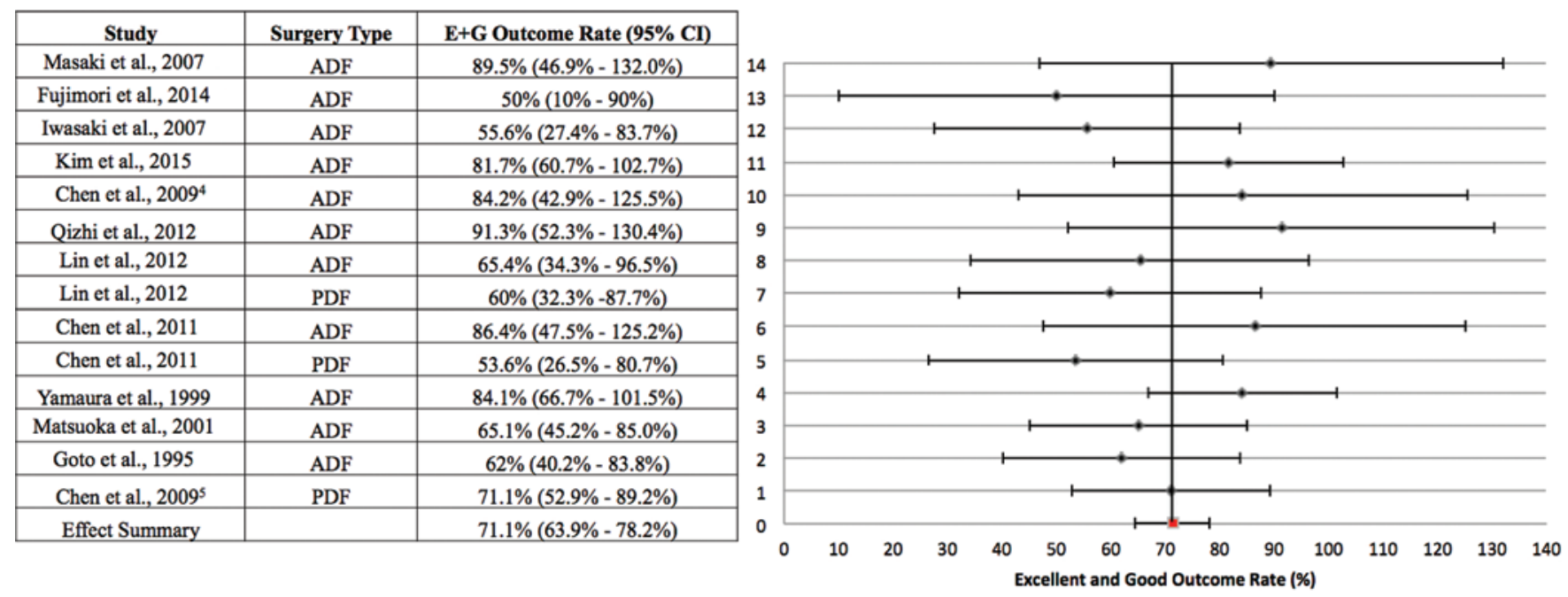

FIG. 2. Excellent and good $(E+G)$ outcomes, $95 \% \mathrm{Cls}$, and forest plot for meta-analysis of fusion studies in systematic review.

\begin{tabular}{|c|c|c|}
\hline Study & Surgery Type & E+G Outcome Rate (95\% CI) \\
\hline Masaki et al., 2007 & Laminoplasty & $67.5 \%(42.0 \%-93.0 \%)$ \\
\hline Fujimori et al., 2014 & Laminoplasty & $26.7 \%(5.3 \%-52.8 \%)$ \\
\hline Iwasaki et al., 2007 & Laminoplasty & $65.2 \%(45.7 \%-84.6 \%)$ \\
\hline Kim et al., 2015 & Laminoplasty & $68.8 \%(48.4 \%-89.1 \%)$ \\
\hline Chen et al., 2011 & Laminoplasty & $28 \%(7.3 \%-48.7 \%)$ \\
\hline Baba et al., 1995 & Laminoplasty & $74.5 \%(49.8 \%-99.1 \%)$ \\
\hline Cho et al., 2008 & Laminectomy & $42.9 \%(8.6 \%-77.2 \%)$ \\
\hline Effect Summary & & $54.0 \%(38.6 \%-69.3 \%)$ \\
\hline
\end{tabular}

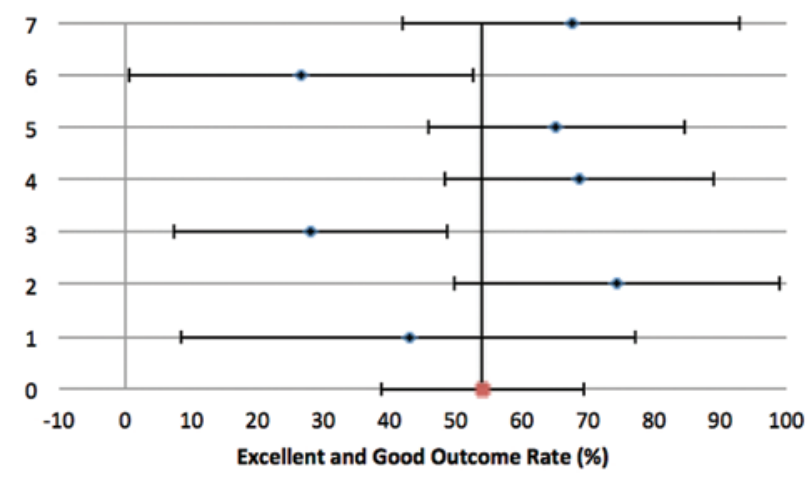

FIG. 3. Excellent and good outcomes, $95 \% \mathrm{Cls}$, and forest plot for meta-analysis of posterior decompression studies in systematic review.

\begin{tabular}{|c|c|c|}
\hline Study & Surgery Type & F+P Outcome Rate (95\% CI) \\
\hline Masaki et al., 2007 & ADF & $10.5 \%(-4.1 \%-25.1 \%)$ \\
\hline Fujimori et al., 2014 & ADF & $50.0 \%(10.0 \%-90.0 \%)$ \\
\hline Iwasaki et al., 2007 & ADF & $44.4 \%(19.3 \%-69.6 \%)$ \\
\hline Kim et al., 2015 & ADF & $18.3 \%(8.4 \%-28.3 \%)$ \\
\hline Chen et al., 20094 & ADF & $15.8 \%(-2.1 \%-33.7 \%)$ \\
\hline Qizhi et al., 2012 & ADF & $8.7 \%(-3.4 \%-20.7 \%)$ \\
\hline Lin et al., 2012 & ADF & $34.6 \%(12.0 \%-57.2 \%)$ \\
\hline Lin et al., 2012 & PDF & $40.0 \%(17.4 \%-62.6 \%)$ \\
\hline Chen et al., 2011 & ADF & $13.6 \%(-1.8 \%-29.1 \%)$ \\
\hline Chen et al., 2011 & PDF & $46.4 \%(21.2 \%-71.7 \%)$ \\
\hline Yamaura et al., 1999 & ADF & $15.9 \%(8.3 \%-23.4 \%)$ \\
\hline Matsuoka et al., 2001 & ADF & $34.9 \%(20.3 \%-49.5 \%)$ \\
\hline Goto et al., 1995 & ADF & $38.0 \%(20.9 \%-55.1 \%)$ \\
\hline Chen et al., 20095 & PDF & $28.9 \%(17.3 \%-40.5 \%)$ \\
\hline Effect Summary & & $24.8 \%(18.3 \%-31.3 \%)$ \\
\hline
\end{tabular}

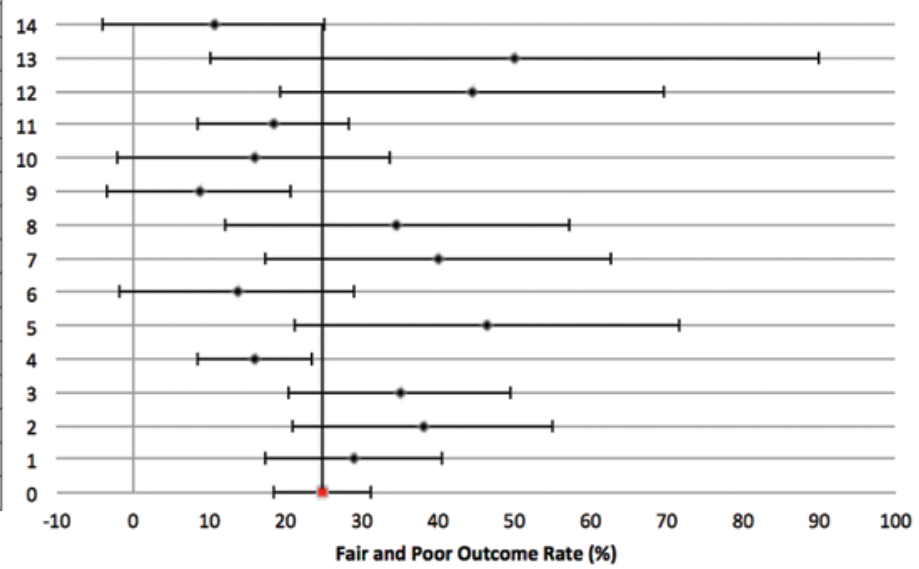

FIG. 4. Fair and poor $(\mathrm{F}+\mathrm{P})$ outcomes, $95 \% \mathrm{Cls}$, and forest plot for meta-analysis of fusion studies in systematic review. 


\begin{tabular}{|c|c|c|}
\hline Study & Surgery Type & F+P Outcome Rate (95\% CI) \\
\hline Masaki et al., 2007 & Laminoplasty & $32.5 \%(14.8 \%-50.2 \%)$ \\
\hline Fujimori et al., 2014 & Laminoplasty & $73.3 \%(30.0 \%-116.7 \%)$ \\
\hline Iwasaki et al., 2007 & Laminoplasty & $34.8 \%(20.6 \%-49.1 \%)$ \\
\hline Kim et al., 2015 & Laminoplasty & $31.3 \%(17.6 \%-44.9 \%)$ \\
\hline Chen et al., 2011 & Laminoplasty & $72 \%(38.7 \%-105.3 \%)$ \\
\hline Baba et al., 1995 & Laminoplasty & $25.5 \%(11.1 \%-40.0 \%)$ \\
\hline Cho et al., 2008 & Laminectomy & $57.1 \%(17.5 \%-96.7 \%)$ \\
\hline Effect Summary & & $37.8 \%(27.3 \%-48.2 \%)$ \\
\hline
\end{tabular}

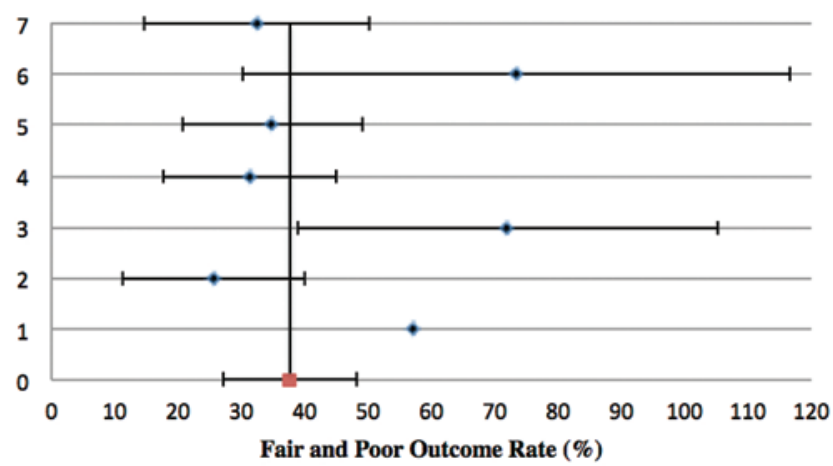

FIG. 5. Fair and poor outcomes, $95 \% \mathrm{Cls}$, and forest plot for meta-analysis of posterior decompression studies in systematic review.

covery rate $(63.2 \%$ vs $53.9 \%$; $p<0.0001)$ compared with the posterior decompression cohort (Tables 3 and 4).

\section{Complications and Revision Operation Rates in Patients Who Underwent Decompression and Fusion Versus Posterior Decompression Only}

Any complications and/or revision operations that were documented for each of the 32 included studies were reviewed and analyzed. Among the 1222 patients who received decompression and fusion surgery, there were a total of 217 complications and 41 unique revision surgeries. The overall prevalence of complications was $14.6 \%$ (95\% CI 10.7\%-18.4\%) (Fig. 6), and the overall prevalence of revision operations was $0.59 \%(95 \% \mathrm{CI} 0.06 \%-1.1 \%)$. The 3 most common complications were C-5 palsy (55 of 217; $25.3 \%$ ), dural tears (50 of $217 ; 23.0 \%$ ), and hoarseness/dysphagia (40 of 217; 18.4\%). The 3 most common causes for revision surgeries were inadequate decompression (10 of $41 ; 24.4 \%$ ), epidural hematoma ( 8 of $41 ; 19.5 \%$ ), and CSF leak/dural defect $(8$ of $41 ; 19.5 \%$ ) (Table 5). An analysis of the studies indicated a high heterogeneity, with an $\mathrm{I}^{2}$ value of $88 \%$. Chen et al. reported the greatest number of complications (in 45 of 133 [33.8\%] patients), and Kim et al. reported the greatest number of revision operations (in 9 of 71 [12.7\%] patients). ${ }^{8,25}$

In the decompression-only population of 745 patients, there were a total of 108 complications and 4 unique revision surgeries. The incidence of complications was $11.8 \%$ (95\% CI 7.6\%-15.9\%) (Fig. 7), and the incidence of revision operations was $0.24 \%$ (95\% CI $0.06 \%-0.43 \%$ ). The 3 most common complications were neurological deterioration (defined as a decrease in JOA score of $>2$ points) (42 of 108 [38.9\%]); arm and axial pain (36 of 108 [33.3\%]); and C-5 palsy (17 of 108 [15.7\%]). Revision operations were required for 3 cases of epidural hematoma and 1 case of OPLL progression (Tables 6 and 7). An analysis of the studies indicated a high heterogeneity, with an $\mathrm{I}^{2}$ value of $83 \%$. Kawaguchi et al. reported the greatest number of complications (in 20 of 45 [44.4\%] patients), and Fujimori et al. reported the greatest number of revision operations (in 2 of 15 [13.3\%] patients). ${ }^{14,24}$

Due to the overlapping CIs for the incidence of complications in the decompression and fusion and the decom- pression-only patient populations, there is no statistically significant difference in the incidence of complications between these 2 populations. There was, however, a statistically significant difference $(\mathrm{p}<0.05)$ when comparing the incidence of certain complications between the decompression and fusion and the posterior decompression-only cohorts. These complications included the following: dural tears/CSF leak (23.0\% in decompression and fusion vs $1.9 \%$ in decompression only, $\mathrm{p}<0.0001)$; $\mathrm{C}-5$ palsy $(25.3 \%$ in decompression and fusion vs $15.7 \%$ in decompression only, $\mathrm{p}=0.01)$; neurological deterioration $(15.2 \%$ in decompression and fusion vs $38.9 \%$ in decompression only, $\mathrm{p}$ $<0.01$ ); arm/axial pain (4.6\% in decompression and fusion vs $33.3 \%$ in decompression only, $\mathrm{p}<0.0001$ ); and hoarseness/dysphagia (18.4\% in decompression and fusion vs $0 \%$ in decompression only, $\mathrm{p}<0.0001$ ) (Table 7). Finally, due to overlapping CIs for the incidence of revision operations in the decompression and fusion and the decompressiononly patient populations, there is no statistically significant difference in the incidence of revision operations between these 2 populations.

\section{Progression of OPLL}

Five studies recorded the progression of the OPLL mass in both the decompression and fusion and the decompression-only populations. . $^{2,31,36,44,48}$ There were a total of 5 cases of OPLL progression among a total of 1222 patients $(0.41 \%)$ in the decompression and fusion population and a total of 48 cases of OPLL progression among a total of 745 patients $(6.4 \%)$ in the posterior decompression-only population.

\section{Discussion}

Decompression with fusion and decompression without fusion are both common treatment options for cervical myelopathy caused by OPLL. To our knowledge, this study is the only comprehensive literature review and meta-analysis of patient outcomes after decompression and fusion or posterior decompression only for OPLL. The purpose of this study was to determine whether the type of surgical treatment affects patient outcomes, to better determine the most appropriate treatment method for patients with 
TABLE 3. Outcome measures of 24 included studies that contained patients who underwent decompression and fusion

\begin{tabular}{|c|c|c|c|c|c|c|}
\hline Authors \& Year & Op Type & Occupying Ratio, \% & $\begin{array}{c}\text { Initial JOA } \\
\text { Score }\end{array}$ & $\begin{array}{c}\text { Final JOA } \\
\text { Score }\end{array}$ & Mean Follow-Up, Yrs & Recovery Rate, \% \\
\hline Masaki et al., 2007 & ADF & 56.0 & 8.3 & 14.2 & 1.0 & 68.4 \\
\hline Fujimori et al., 2014 & ADF & 67.5 & 9.5 & 13.3 & 9.9 & 52.5 \\
\hline Sakai et al., 2012 & ADF & 43.4 & 11.4 & 15.1 & 5.0 & 71.4 \\
\hline Iwasaki et al., 2007 & ADF & 56.6 & 9.6 & 13.1 & 6.0 & 49.0 \\
\hline Kim et al., 2015 & ADF & 56.2 & 12.0 & 15.6 & 4.0 & 72.6 \\
\hline Chen et al., $2009^{4}$ & ADF & 65.4 & 9.3 & 14.2 & 1.5 & 63.2 \\
\hline Lei et al., 2014 & ADF & 62.0 & 8.8 & 14.0 & 2.1 & 63.5 \\
\hline Wang et al., 2012 & ADF & 67.3 & 8.3 & 13.9 & 2.6 & 64.0 \\
\hline Mochizuki et al., 2009 & ADF & 40.0 & 10.2 & 15.1 & 3.6 & 74.6 \\
\hline Qizhi et al., 2012 & ADF & NA & 8.2 & 13.8 & 1.7 & 64.5 \\
\hline Chen et al., 2014 & ADF & 48.4 & 9.6 & 13.7 & 5.0 & 64.1 \\
\hline Lin et al., 2012 & ADF & 54.2 & 9.3 & 14.2 & 3.0 & 58.6 \\
\hline Lin et al., 2012 & PDF & 44.2 & 9.1 & 13.7 & 3.0 & 54.8 \\
\hline Chen et al., $2009^{5}$ & PDF & 43.5 & 9.2 & 14.2 & 4.8 & 62.4 \\
\hline Chen et al., 2011 & ADF & 55.4 & 9.3 & 14.2 & 4.0 & 63.2 \\
\hline Chen et al., 2011 & PDF & 58.2 & 8.7 & 12.4 & 4.0 & 43.5 \\
\hline Kim et al., 2009 & ADF & NA & 11.9 & 15.3 & 2.0 & 71.7 \\
\hline Yuan et al., 2015 & PDF & NA & 10.6 & 13.4 & 1.0 & 50.8 \\
\hline Chen et al., 2012 & ADF & 43.6 & 9.8 & 14.7 & 5.0 & 68.0 \\
\hline Chen et al., 2012 & PDF & 47.1 & 9.1 & 13.0 & 5.0 & 50.8 \\
\hline Katsumi et al., 2015 & PDF & 51.5 & 10.8 & 13.3 & 4.3 & 41.6 \\
\hline Yamaura et al., 1999 & ADF & NA & 8.0 & 14.2 & 3.0 & 71.0 \\
\hline Matsuoka et al., 2001 & ADF & 54.4 & 8.3 & 13.5 & 13.0 & 59.3 \\
\hline Goto \& Kita, 1995 & ADF & 45.9 & 7.8 & 12.8 & 8.7 & 53.9 \\
\hline Odate et al., 2012 & ADF & 43.2 & 12.9 & 15.1 & 2.5 & 63.0 \\
\hline Baba et al., 1995 & ADF & NA & 9.4 & 14.1 & 8.5 & 65.7 \\
\hline Baba et al., 1994 & ADF & NA & 7.0 & 13.5 & 8.3 & 66.2 \\
\hline Average & & 50.2 & 9.4 & 14.0 & 5.2 & 63.2 \\
\hline
\end{tabular}

NA = not applicable (in studies that did not report occupying ratio [\%]).

OPLL. By analyzing patient outcomes based on the surgical approach, JOA scoring, recovery rates, complication rates, revision surgery rates, and OPLL progression rates, we were able to demonstrate clinically important differences among decompression and fusion versus decompression-only surgical procedures.

\section{Recovery Rates in Decompression and Fusion Versus Posterior Decompression Only}

The JOA questionnaire is often used to grade the severity of cervical myelopathy. The JOA scoring is based on upper- and lower-extremity motor and sensory deficits. A higher JOA score indicates fewer neurological deficits. Because JOA scoring relies primarily on patient-reported outcomes (PROs), it can be difficult to determine whether a change in the numerical JOA score correlates with a significant improvement in clinical outcome.

Minimal clinically important difference (MCID) scores are a means to determine whether PROs are of clinical relevance. The MCID for a given intervention is defined as the smallest improvement in a PRO necessary to achieve a patient-perceived improvement in clinical outcome. ${ }^{11} \mathrm{Al}-$ though the MCID of JOA scoring has not been definitely established, Furlan et al. argue that an improvement of 2 points is clinically significant..$^{15}$ Considering this threshold as representative of an MCID, we found a clinically significant postoperative improvement in both the decompression with fusion and decompression-only populations.

However, whereas the preoperative JOA score between the 2 patient populations was the same, we found a statistically significantly higher final JOA score in the decompression and fusion population compared with the posterior decompression-only population. Postoperative kyphotic progression and OPLL mass size are probably 2 important contributors to differences in postoperative JOA scores in the fusion and decompression populations. ${ }^{48}$ Posterior decompression is associated with postoperative loss of cervical lordosis, increasing the chances of longterm neurological deterioration. ${ }^{14,49}$ This deterioration occurs because patients with OPLL who undergo posterior 
TABLE 4. Outcome measures of 14 included studies that contained patients who underwent decompression only

\begin{tabular}{lcccccc}
\hline \multicolumn{1}{c}{ Authors \& Year } & Op Type & Occupying Ratio, $\%$ & $\begin{array}{c}\text { Initial JOA } \\
\text { Score }\end{array}$ & $\begin{array}{c}\text { Final JOA } \\
\text { Score }\end{array}$ & Mean Follow-Up, Yrs & Recovery Rate, \% \\
\hline Masaki et al., 2007 & LP & 55.9 & 8.6 & 13.0 & 1.0 & 52.5 \\
\hline Fujimori et al., 2014 & LP & 66.0 & 9.1 & 11.7 & 10.2 & 30.1 \\
\hline Sakai et al., 2012 & LP & 46.9 & 10.9 & 14.0 & 5.0 & 55.3 \\
\hline Iwasaki et al., 2007 & LP & 44.4 & 9.2 & 14.1 & 10.2 & 58.0 \\
\hline Kim et al., 2015 & LP & 55.1 & 12.0 & 15.0 & 4.0 & 52.0 \\
\hline Chen et al., 2011 & LP & 54.3 & 8.5 & 10.9 & 4.0 & 25.1 \\
\hline Yuan et al., 2015 & LP & NA & 10.6 & 13.4 & 1.0 & 43.7 \\
\hline Chen et al., 2012 & LP & 41.2 & 10.2 & 14.6 & 5.0 & 65.2 \\
\hline Katsumi et al., 2015 & LP & 45.7 & 10.5 & 13.1 & 4.3 & 36.1 \\
\hline Ogawa et al., 2004 & LP & 45.7 & 9.2 & 14.2 & 7.3 & 63.1 \\
\hline Baba et al., 1995 & LP & NA & 8.4 & 13.1 & 3.2 & 54.6 \\
\hline Yang et al., 2007 & LP & NA & 7.5 & 13.2 & 13.1 & 60.1 \\
\hline Kawaguchi et al., 2001 & LP & NA & 8.7 & 14.2 & 7.0 & 63.3 \\
\hline Goto \& Kita, 1995 & LP & NA & 7.6 & 12.6 & 3.4 & 52.8 \\
\hline Cho et al., 2008 & LA & NA & 11.9 & 13.9 & 4.8 & 43.5 \\
\hline Lee et al., 2016 & LA & NA & 10.7 & 14.3 & 14.1 & 56.3 \\
\hline Kato et al., 1998 & LA & 54.8 & 7.6 & 10.3 & 3.6 & 32.8 \\
\hline Zhao et al., 2012 & LA & NA & 8.4 & 13.9 & 13.5 & 54.0 \\
\hline Average & & 49.8 & 9.2 & & 53.9 \\
\hline
\end{tabular}

decompression alone have a significant posterior shifting of the spinal cord and possible tethering of the spinal cord to the OPLL mass. ${ }^{5}$

Yamazaki et al. reported that cervical lordosis $<10^{\circ}$ or an OPLL mass that is thicker than $7 \mathrm{~mm}$ is associated with an increased risk for spinal cord contact with the ossified mass and development of neurological symptoms. ${ }^{57}$ Furthermore, laminoplasty, specifically, has been correlated with progressive kyphosis and subsequent neurological deterioration at long-term follow-up, probably accounting for our findings of an increased recovery rate in the decompression and fusion population. ${ }^{28,51}$ Although outcomes after laminoplasty for a large OPLL mass are poor, ${ }^{32}$ previous studies have shown that higher preoperative lordosis is associated with better outcomes after laminoplasty in patients with a large OPLL mass. ${ }^{14}$

\begin{tabular}{|c|c|c|}
\hline Study & Surgery Type & Complication Rate (95\% CI) \\
\hline Fujimori et al., 2014 & ADF & $25.0 \%(-3.3 \%-53.3 \%)$ \\
\hline Sakai et al., 2012 & ADF & $25.0 \%(3.1 \%-46.9 \%)$ \\
\hline Iwasaki et al., 2007 & ADF & $29.6 \%(9.1 \%-50.2 \%)$ \\
\hline Kim et al., 2015 & ADF & $26.8 \%(14.7 \%-38.8 \%)$ \\
\hline Chen et al., 20094 & ADF & $31.6 \%(6.3 \%-56.8 \%)$ \\
\hline Lei et al., 2014 & ADF & $22.7 \%(2.8 \%-42.6 \%)$ \\
\hline Wang et al., 2012 & ADF & $17.2 \%(2.1 \%-32.4 \%)$ \\
\hline Qizhi et al., 2012 & ADF & $13.0 \%(-1.7 \%-27.8 \%)$ \\
\hline Chen et al., 2014 & ADF & $33.8 \%(23.9 \%-43.7 \%)$ \\
\hline Lin et al., 2012 & ADF & $11.5 \%(-1.5 \%-24.6 \%)$ \\
\hline Lin et al., 2012 & PDF & $6.7 \%(-2.6 \%-15.9 \%)$ \\
\hline Chen et al., 20095 & PDF & $11.2 \%(5.5 \%-16.9 \%)$ \\
\hline Chen et al., 2011 & ADF & $22.7 \%(2.8 \%-42.6 \%)$ \\
\hline Chen et al., 2011 & PDF & $25.0 \%(6.5 \%-43.5 \%)$ \\
\hline Kim et al., 2009 & ADF & $5.9 \%(-5.6 \%-17.4 \%)$ \\
\hline Yuan et al., 2015 & PDF & $33.3 \%(6.7 \%-60 \%)$ \\
\hline Chen et al., 2012 & ADF & $17.6 \%(9.0 \%-26.2 \%)$ \\
\hline Chen et al., 2012 & PDF & $37.5 \%(16.3 \%-58.7 \%)$ \\
\hline Katsumi et al., 2015 & PDF & $10.5 \%(-4.1 \%-25.1 \%)$ \\
\hline Yamaura et al., 1999 & ADF & $11.2 \%(4.9 \%-17.6 \%)$ \\
\hline Matsuoka et al., 2001 & ADF & $9.5 \%(1.9 \%-17.1 \%)$ \\
\hline Goto et al., 1995 & ADF & $28.0 \%(13.3 \%-42.7 \%)$ \\
\hline Odate et al., 2012 & ADF & $14.7 \%(5.6 \%-23.8 \%)$ \\
\hline Baba et al., 1995 & ADF & $4.7 \%(0.1 \%-9.3 \%)$ \\
\hline Baba et al., 1994 & ADF & $0.1 \%(-0.6 \%-0.8 \%)$ \\
\hline Masaki et al., 2007 & ADF & $0.5 \%(-2.7 \%-3.8 \%)$ \\
\hline Mochizuki et al., 2009 & ADF & $0.5 \%(-2.6 \%-3.6 \%)$ \\
\hline Summary & & $14.6 \%(10.7 \%-18.4 \%)$ \\
\hline
\end{tabular}

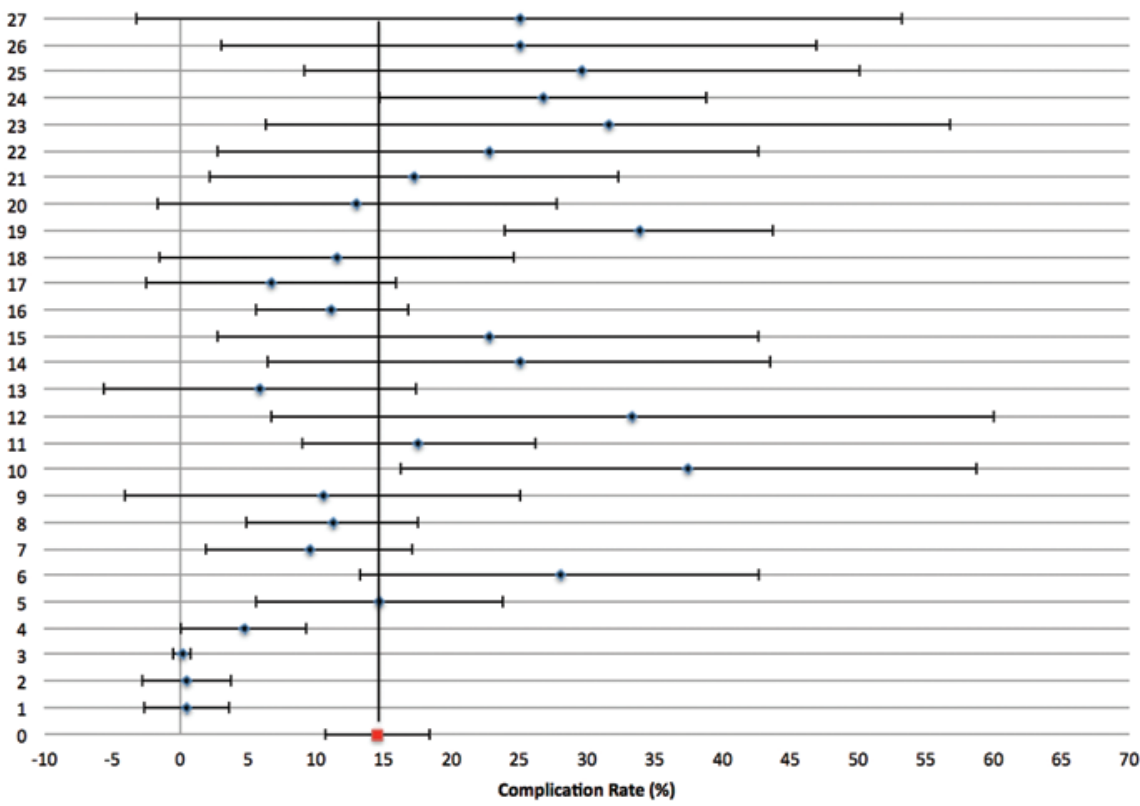

FIG. 6. Complication rate, $95 \% \mathrm{Cls}$, and forest plot for meta-analysis of fusion studies in systematic review. 
TABLE 5. Complication and revision rates in decompression and fusion patient populations

\begin{tabular}{|c|c|c|c|c|}
\hline Authors \& Year & Op Type & Mean Follow-Up, Yrs & No. of Complications (\%) & No. of Revisions (\%) \\
\hline Masaki et al., 2007 & ADF & 1.0 & 0 & 0 \\
\hline Fujimori et al., 2014 & ADF & 9.9 & $3(25)$ & $4(33)$ \\
\hline Sakai et al., 2012 & ADF & 5.0 & $5(20)$ & $3(15)$ \\
\hline Iwasaki et al., 2007 & ADF & 6.0 & $8(29)$ & $7(26)$ \\
\hline Kim et al., 2015 & ADF & 4.0 & $19(27)$ & $9(13)$ \\
\hline Chen et al., $2009^{4}$ & ADF & 1.5 & $6(32)$ & $1(5)$ \\
\hline Lei et al., 2014 & ADF & 2.1 & $8(36)$ & $1(5)$ \\
\hline Wang et al., 2012 & ADF & 2.6 & $5(17)$ & $1(3)$ \\
\hline Mochizuki et al., 2009 & ADF & 3.6 & 0 & 0 \\
\hline Qizhi et al., 2012 & ADF & 1.7 & $3(13)$ & $1(4)$ \\
\hline Chen et al., 2014 & ADF & 5.0 & $45(34)$ & $2(1)$ \\
\hline Lin et al., 2012 & ADF & 3.0 & $2(8)$ & 0 \\
\hline Lin et al., 2012 & PDF & 3.0 & $3(10)$ & $1(3)$ \\
\hline Chen et al., $2009^{5}$ & PDF & 4.8 & $15(11)$ & $3(2)$ \\
\hline Chen et al., 2011 & ADF & 4.0 & $5(22)$ & 0 \\
\hline Chen et al., 2011 & PDF & 4.0 & $7(25)$ & 0 \\
\hline Kim et al., 2009 & ADF & 2.0 & $1(6)$ & $1(6)$ \\
\hline Yuan et al., 2015 & PDF & 1.0 & $6(33)$ & 0 \\
\hline Chen et al., 2012 & ADF & 5.0 & $16(18)$ & 0 \\
\hline Chen et al., 2012 & PDF & 5.0 & $12(38)$ & 0 \\
\hline Katsumi et al., 2015 & PDF & 4.3 & $2(11)$ & 0 \\
\hline Yamaura et al., 1999 & ADF & 3.0 & $12(11)$ & 0 \\
\hline Matsuoka et al., 2001 & ADF & 13.0 & $6(10)$ & $5(8)$ \\
\hline Goto \& Kita, 1995 & ADF & 8.7 & $14(28)$ & 0 \\
\hline Odate et al., 2012 & ADF & 2.5 & $10(15)$ & $2(3)$ \\
\hline Baba et al., 1995 & ADF & 8.5 & 0 & 0 \\
\hline Baba et al., 1994 & ADF & 8.3 & $4(5)$ & 0 \\
\hline Total & & 5.2 & 217 & 41 \\
\hline
\end{tabular}

\begin{tabular}{|c|c|c|}
\hline Study & Surgery Type & Complication Rate (95\% CI) \\
\hline Masaki et al., 2007 & Laminoplasty & $2.5 \%(-2.4 \%-7.4 \%)$ \\
\hline Fujimori et al., 2014 & Laminoplasty & $20 \%(-2.6 \%-42.6 \%)$ \\
\hline Sakai et al., 2012 & Laminoplasty & $22.7 \%(2.8 \%-42.6 \%)$ \\
\hline Iwasaki et al., 2007 & Laminoplasty & $4.5 \%(-0.6 \%-9.7 \%)$ \\
\hline Goto et al., 1995 & Laminoplasty & $29.2 \%(16.1 \%-42.4 \%)$ \\
\hline Chen et al., 2011 & Laminoplasty & $32 \%(9.8 \%-54.2 \%)$ \\
\hline Yuan et al., 2015 & Laminoplasty & $20 \%(0.4 \%-39.6 \%)$ \\
\hline Chen et al., 2012 & Laminoplasty & $17.1 \%(4.4 \%-29.7 \%)$ \\
\hline Katsumi et al., 2015 & Laminoplasty & $13.6 \%(-1.8 \%-29.1 \%)$ \\
\hline Ogawa et al., 2004 & Laminoplasty & $22.2 \%(11.3 \%-33.1 \%)$ \\
\hline Baba et al., 1995 & Laminoplasty & $6.4 \%(-0.8 \%-13.6 \%)$ \\
\hline Yang et al., 2007 & Laminoplasty & $3.7 \%(-3.6 \%-11.0 \%)$ \\
\hline Kawaguchi et al., 2001 & Laminoplasty & $44.4 \%(25.0 \%-63.9 \%)$ \\
\hline Cho et al., 2008 & Laminectomy & $28.6 \%(0.6 \%-56.6 \%)$ \\
\hline Lee et al., 2016 & Laminectomy & $11.8 \%(0.2 \%-23.3 \%)$ \\
\hline Kato et al., 1998 & Laminectomy & $11.4 \%(1.4 \%-21.3 \%)$ \\
\hline Kim et al., 2015 & Laminoplasty & $0.2 \%(-0.8 \%-1.12 \%)$ \\
\hline Effect Summary & & $11.8 \%(7.6 \%-15.9 \%)$ \\
\hline
\end{tabular}

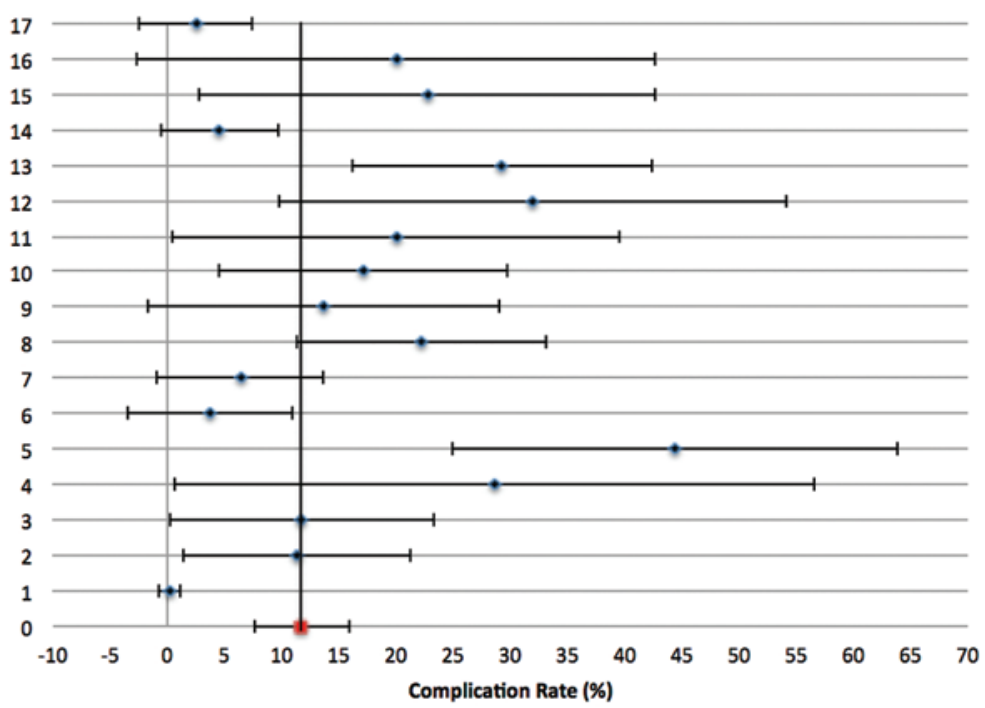

FIG. 7. Complication rate, $95 \% \mathrm{Cls}$, and forest plot for meta-analysis of posterior decompression studies in systematic review. 
TABLE 6. Complication and revision rates in decompression-only patient population

\begin{tabular}{lcccc}
\hline \multicolumn{1}{c}{ Authors \& Year } & Op Type & Mean Follow-Up, Yrs & No. of Complications (\%) & No. of Revisions (\%) \\
\hline Masaki et al., 2007 & LP & 1.0 & $1(2.5)$ & 0 \\
\hline Fujimori et al., 2014 & LP & 10.2 & $3(20)$ & 0 \\
\hline Sakai et al., 2012 & LP & 5.0 & $5(23)$ & $1(2)$ \\
\hline Iwasaki et al., 2007 & LP & 10.2 & $3(5)$ & NA \\
\hline Kim et al., 2015 & LP & 4.0 & 0 & $1(4)$ \\
\hline Chen et al., 2011 & LP & 4.0 & $8(32)$ & 0 \\
\hline Yuan et al., 2015 & LP & 1.0 & $4(20)$ & 0 \\
\hline Chen et al., 2012 & LP & 5.0 & $7(17)$ & 0 \\
\hline Katsumi et al., 2015 & LP & 4.3 & $3(14)$ & 0 \\
\hline Ogawa et al., 2004 & LP & 9.5 & $3(22)$ & 0 \\
\hline Baba et al., 1995 & LP & 7.3 & $1(4)$ & 0 \\
\hline Yang et al., 2007 & LP & 3.2 & $20(44)$ & 0 \\
\hline Kawaguchi et al., 2001 & LP & 13.1 & $19(29)$ & 0 \\
\hline Goto \& Kita, 1995 & LP & 7.0 & $4(29)$ & 0 \\
\hline Cho et al., 2008 & LA & 3.4 & $4(12)$ & 0 \\
\hline Lee et al., 2016 & LA & 4.8 & $5(11)$ & 0 \\
\hline Kato et al., 1998 & LA & 14.1 & 108 & 4 \\
\hline Zhao et al., 2012 & LA & 3.5 & 6.6 & \\
\hline Total & & & \\
\hline
\end{tabular}

\section{Complications and Revision Surgeries in Patients Who Underwent Decompression and Fusion Versus Posterior Decompression Only}

Many studies have observed postsurgical complications after either decompression and fusion or posterior decom-

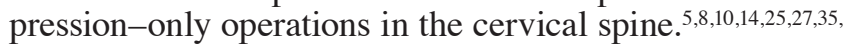
$44,46,48,50,52$ Some of the most commonly reported complications after cervical decompression and fusion surgery include CSF leaks and pseudarthrosis, whereas posterior decompression is more commonly associated with neurological deterioration, persistent neuropathic pain in the extremities, and progression of kyphotic change. ${ }^{6,14}$

Previous studies have demonstrated an increased incidence of complications after decompression and fusion compared with decompression only. In a multicenter retrospective study by Kimura et al. of 150 patients who underwent ADF for OPLL, upper- and lower-extremity motor deterioration occurre in $13.3 \%$ and $2 \%$ of patients, respectively. ${ }^{27}$ In contrast, in a study by Seichi et al. that reported outcomes of 581 patients with OPLL who underwent laminoplasty, postoperative upper- and lower-extremity motor deterioration were reported in only $4 \%$ and $3.1 \%$ of patients, respectively. ${ }^{50}$

In the current study, we found no statistically significant difference in the incidence of total complications in the decompression and fusion and the decompression-only populations. There was, however, a statistically significant difference in the incidence of specific complications in each population. Decompression and fusion surgery was associated with a higher incidence of postoperative CSF leak, whereas neurological deterioration, and neuropathic arm and axial pain were more common in the decompression-only population.

The increased likelihood of CSF leak in our meta-anal- ysis is probably due to the propensity toward anterior approaches in the fusion population, in which direct removal of the tethered OPLL mass disrupts the underlying dura mater and thereby causes the CSF leak. In the decompression-only population, the progression of kyphotic deformity and the tethering of nerve roots due to incomplete decompression of the spinal cord are the major causes of neurological deterioration. Furthermore, arm and axial neuropathic pain is suspected to occur due to disruption of posterior neck tissue. ${ }^{3}$

An important limitation in our analysis of complications is that we are unable to distinguish the severity of

TABLE 7. Distribution of complications in decompression and fusion and in decompression-only patient populations

\begin{tabular}{lccc}
\hline \multicolumn{1}{c}{ Complication } & $\begin{array}{c}\text { Decompression } \\
\text { \& Fusion, No. (\%) }\end{array}$ & $\begin{array}{c}\text { Decompression } \\
\text { Only, No. (\%) }\end{array}$ & p Value \\
\hline Dural tear/CSF leak & $50(23.0)$ & $2(1.9)$ & $<0.0001^{*}$ \\
\hline C-5 palsy & $55(25.3)$ & $17(15.7)$ & $0.01^{*}$ \\
\hline Pseudarthrosis & $5(2.3)$ & 0 & 0.2 \\
\hline Hematoma & $7(3.2)$ & $5(4.6)$ & 0.8 \\
\hline $\begin{array}{l}\text { Bone graft dislocation } \\
\begin{array}{l}\text { Neurological deterio- } \\
\text { ration }\end{array}\end{array}$ & $4(1.8)$ & 0 & 0.3 \\
\hline $\begin{array}{l}\text { Arm/axial pain } \\
\text { Hoarseness/dys- } \\
\text { phagia }\end{array}$ & $10(4.6)$ & $42(38.9)$ & $<0.01^{*}$ \\
\hline Other & $40(18.4)$ & $36(33.3)$ & $<0.0001^{*}$ \\
\hline Total & $13(6.2)$ & $6(5.6)$ & $<0.0001^{*}$ \\
\hline
\end{tabular}

* Indicates a statistically significant difference $(p<0.05)$. 
specific postoperative complications. For example, although the incidence of dysphagia was statistically significantly different between the 2 patient populations, the consequences of this complication may have ranged from minor difficulty in swallowing to requiring tube feeding. It is also worth noting that certain complications, such as C-5 palsy, have a more significant impact on quality of life than others.

\section{Postoperative Progression of an Ossified Mass in Patients Who Underwent Decompression and Fusion Versus Posterior Decompression Only}

Previous studies suggest that decompression without fusion not only fails to decrease the rate of progression of OPLL, but may also lead to an acceleration of progression. Hori et al. retrospectively studied 55 patients with an average 10-year follow-up who underwent laminoplasty for OPLL. The authors found that OPLL progressed postoperatively in $71 \%$ of patients. ${ }^{18}$ Similarly, a study by Chiba et al. that retrospectively evaluated 131 patients who underwent a decompression-only procedure for OPLL reported progression of OPLL in $56.5 \%$ of patients after only 2 years. ${ }^{9}$

Other studies have found decompression-only operations to cause higher rates of OPLL progression compared with conservative treatment. Takatsu et al. studied the progression of OPLL over a 3-year follow-up in 44 patients who received posterior decompression only or conservative treatment. The authors found that the progression of OPLL was increased in the surgical group compared with the conservative group $(\mathrm{p}<0.01) .{ }^{53}$ Given these findings in the literature, Sugrue et al. recommend against performing posterior decompression in the form of laminectomy or laminoplasty due to the concern of OPLL progression. ${ }^{52}$ In addition, Onari et al. argued that decompression and fusion may slow the rate of progression when compared with decompression alone. ${ }^{45}$

Several studies in the literature support this position. Katsumi et al. retrospectively compared OPLL progression in 19 patients who received PDF and in 22 patients who received laminoplasty. The authors found a statistically significantly slower rate of progression of OPLL in the PDF population compared with the laminoplasty population. The annual rate of increase was $2.0 \% \pm 1.7 \%$ in the PDF group compared with $7.5 \% \pm 5.6 \%$ in the decompression-only group $(\mathrm{p}<0.0001) .^{23}$

Similarly, Lee et al. reviewed 57 patients who underwent laminectomy, laminoplasty, or PDF. The authors found a decreased rate of progression in the PDF population compared with laminectomy and/or laminoplasty populations $(\mathrm{p}<0.05) .{ }^{29}$ Our findings support this hypothesis. We found the incidence of OPLL progression to be statistically significantly lower in the decompression and fusion population compared with the decompression-only population $(\mathrm{p}<0.0001)$.

These findings may be explained by accelerated ectopic ossification of the PLL in patients who do not receive fusion. According to Wolff's law, bone remodeling occurs in areas of increased biomechanical stress. ${ }^{47}$ In fusions, the rigidity of the construct may slow the progression of OPLL due to a lack of biomechanical segmental shear- ing forces. In contrast, decompression without fusion allows for increased vertebral movement, thereby causing increased biomechanical stress and reactive bone formation. Future studies are warranted to further analyze the mechanism of OPLL progression in patients who receive decompression and fusion or decompression alone.

\section{Limitations of the Study}

As with any study, the current work has limitations. One limitation of this meta-analysis is that the majority of included studies do not stratify their postoperative outcomes on a yearly basis. Instead they used mean follow-up times, with ranges that varied. The variance between individual studies ranged from a follow-up time of 1 year to $>13$ years. Patients with a longer follow-up may be more likely to demonstrate progression of OPLL and the neurological deterioration associated with that progression.

Furthermore, the majority of the studies included in this review are retrospective in design. Retrospective studies are associated with inherent bias. Unfortunately, performing randomized clinical trials in this patient population would be challenging due to the discrepant opinions regarding the optimal surgical approach for different patient presentations. Only patients who were deemed suitable candidates for either decompression and fusion or decompression only could be compared in randomized clinical trials.

Finally, although indications for anterior or posterior decompression in patients with OPLL overlap substantially, certain clinical scenarios favor 1 approach over the other. However, due to the limited number of studies that focus on PDF, we were unable to directly compare the progression of OPLL in patients who underwent PDF versus posterior decompression alone. As a result, future studies are necessary to more definitively illustrate the benefits of decompression and fusion over decompression alone.

\section{Conclusions}

Both ADF or PDF surgery and decompression without fusion are common surgical strategies for treating cervical myelopathy due to OPLL. The aim of this study was to better define clinical outcomes related to each procedure in patients with OPLL. Our results suggest that surgical decompression with fusion is associated with a faster recovery, improved neurological function, and a lower incidence of OPLL progression compared with decompression alone. Furthermore, decompression and fusion surgery had a similar complication rate when compared with posterior decompression only. Given these findings, decompression and fusion seems to be a superior surgical technique compared with posterior decompression alone in patients with OPLL. Future prospective studies are warranted to better elucidate the benefits of cervical decompression and fusion versus decompression only in patients with OPLL.

\section{References}

1. Baba H, Furusawa N, Tanaka Y, Wada M, Imura S, Tomita K: Anterior decompression and fusion for cervical myeloradiculopathy secondary to ossification of the posterior ligament.

Int Orthop 18:204-209, 1994 
2. Baba H, Imura S, Kawahara N, Nagata S, Tomita K: Osteoplastic laminoplasty for cervical myeloradiculopathy secondary to ossification of the posterior longitudinal ligament. Int Orthop 19:40-45, 1995

3. Benzel EC, Francis TB: Spine Surgery: Techniques, Complication Avoidance, and Management, ed 3. Philadelphia: Elsevier/Saunders, 2012

4. Chen Y, Chen D, Wang X, Lu X, Guo Y, He Z, et al: Anterior corpectomy and fusion for severe ossification of posterior longitudinal ligament in the cervical spine. Int Orthop 33:477-482, 2009

5. Chen Y, Guo Y, Chen D, Wang X, Lu X, Yuan W: Long-term outcome of laminectomy and instrumented fusion for cervical ossification of the posterior longitudinal ligament. Int Orthop 33:1075-1080, 2009

6. Chen Y, Guo Y, Lu X, Chen D, Song D, Shi J, et al: Surgical strategy for multilevel severe ossification of posterior longitudinal ligament in the cervical spine. J Spinal Disord Tech 24:24-30, 2011

7. Chen Y, Liu X, Chen D, Wang X, Yuan W: Surgical strategy for ossification of the posterior longitudinal ligament in the cervical spine. Orthopedics 35:e1231-e1237, 2012

8. Chen Y, Yang L, Liu Y, Yang H, Wang X, Chen D: Surgical results and prognostic factors of anterior cervical corpectomy and fusion for ossification of the posterior longitudinal ligament. PLoS One 9:e102008, 2014

9. Chiba K, Yamamoto I, Hirabayashi H, Iwasaki M, Goto H, Yonenobu K, et al: Multicenter study investigating the postoperative progression of ossification of the posterior longitudinal ligament in the cervical spine: a new computer-assisted measurement. J Neurosurg Spine 3:17-23, 2005

10. Cho WS, Chung CK, Jahng TA, Kim HJ: Post-laminectomy kyphosis in patients with cervical ossification of the posterior longitudinal ligament: does it cause neurological deterioration? J Korean Neurosurg Soc 43:259-264, 2008

11. Cook CE: Clinimetrics corner: the Minimal Clinically Important Change score (MCID): a necessary pretense. J Manual Manip Ther 16:E82-E83, 2008

12. DeLong WB, Polissar N, Neradilek B: Timing of surgery in cauda equina syndrome with urinary retention: meta-analysis of observational studies. J Neurosurg Spine 8:305-320, 2008

13. Epstein NE: The surgical management of ossification of the posterior longitudinal ligament in 43 North Americans. Spine (Phila Pa 1976) 19:664-672, 1994

14. Fujimori T, Iwasaki M, Okuda S, Takenaka S, Kashii M, Kaito T, et al: Long-term results of cervical myelopathy due to ossification of the posterior longitudinal ligament with an occupying ratio of $60 \%$ or more. Spine (Phila Pa 1976) 39:58-67, 2014

15. Furlan JC, Kalsi-Ryan S, Kailaya-Vasan A, Massicotte EM, Fehlings MG: Functional and clinical outcomes following surgical treatment in patients with cervical spondylotic myelopathy: a prospective study of 81 cases. J Neurosurg Spine 14:348-355, 2011

16. Goto S, Kita T: Long-term follow-up evaluation of surgery for ossification of the posterior longitudinal ligament. Spine (Phila Pa 1976) 20:2247-2256, 1995

17. Hirabayashi K, Miyakawa J, Satomi K, Maruyama T, Wakano K: Operative results and postoperative progression of ossification among patients with ossification of cervical posterior longitudinal ligament. Spine (Phila Pa 1976) 6:354-364, 1981

18. Hori T, Kawaguchi Y, Kimura T: How does the ossification area of the posterior longitudinal ligament progress after cervical laminoplasty? Spine (Phila Pa 1976) 31:2807-2812, 2006

19. Iwasaki M, Kawaguchi Y, Kimura T, Yonenobu K: Longterm results of expansive laminoplasty for ossification of the posterior longitudinal ligament of the cervical spine: more than 10 years follow up. J Neurosurg 96 (2 Suppl):180-189, 2002

20. Iwasaki M, Okuda S, Miyauchi A, Sakaura H, Mukai Y, Yonenobu K, et al: Surgical strategy for cervical myelopathy due to ossification of the posterior longitudinal ligament: Part 2: Advantages of anterior decompression and fusion over laminoplasty. Spine (Phila Pa 1976) 32:654-660, 2007

21. Kalb S, Martirosyan NL, Perez-Orribo L, Kalani MY, Theodore N: Analysis of demographics, risk factors, clinical presentation, and surgical treatment modalities for the ossified posterior longitudinal ligament. Neurosurg Focus 30(3):E11, 2011

22. Kato Y, Iwasaki M, Fuji T, Yonenobu K, Ochi T: Long-term follow-up results of laminectomy for cervical myelopathy caused by ossification of the posterior longitudinal ligament. J Neurosurg 89:217-223, 1998

23. Katsumi K, Izumi T, Ito T, Hirano T, Watanabe K, Ohashi M: Posterior instrumented fusion suppresses the progression of ossification of the posterior longitudinal ligament: a comparison of laminoplasty with and without instrumented fusion by three-dimensional analysis. Eur Spine J 25:16341640,2016

24. Kawaguchi Y, Kanamori M, Ishihara H, Nakamura H, Sugimori K, Tsuji H, et al: Progression of ossification of the posterior longitudinal ligament following en bloc cervical laminoplasty. J Bone Joint Surg Am 83-A:1798-1802, 2001

25. Kim B, Yoon H, Shin HC, Kim KN, Yi S, Shin DA, et al: Surgical outcome and prognostic factors of anterior decompression and fusion for cervical compressive myelopathy due to ossification of the posterior longitudinal ligament. Spine J 15:875-884, 2015

26. Kim K, Isu T, Sugawara A, Morimoto D, Matsumoto R, Isobe $\mathrm{M}$, et al: Treatment of cervical OPLL by cervical anterior fusion using autologous vertebral bone grafts. Acta Neurochir (Wien) 151:1549-1555, 2009

27. Kimura A, Seichi A, Hoshino Y, Yamazaki M, Mochizuki M, Aiba A, et al: Perioperative complications of anterior cervical decompression with fusion in patients with ossification of the posterior longitudinal ligament: a retrospective, multi-institutional study. J Orthop Sci 17:667-672, 2012

28. Kimura I, Shingu H, Nasu Y: Long-term follow-up of cervical spondylotic myelopathy treated by canal-expansive laminoplasty. J Bone Joint Surg Br 77:956-961, 1995

29. Lee CH, Jahng TA, Hyun SJ, Kim KJ, Kim HJ: Expansive laminoplasty versus laminectomy alone versus laminectomy and fusion for cervical ossification of the posterior longitudinal ligament: is there a difference in the clinical outcome and sagittal alignment? Clin Spine Surg 29:E9-E15, 2016

30. Lei T, Shen Y, Wang LF, Ding WY, Zhang D, Zhang P, et al: Anterior longitudinal decompression in the management of severe ossification of the posterior longitudinal ligament in the cervical spine. Orthopedics 37:e465-e472, 2014

31. Lin D, Ding Z, Lian K, Hong J, Zhai W: Cervical ossification of the posterior longitudinal ligament: Anterior versus posterior approach. Indian J Orthop 46:92-98, 2012

32. Masaki Y, Yamazaki M, Okawa A, Aramomi M, Hashimoto M, Koda M, et al: An analysis of factors causing poor surgical outcome in patients with cervical myelopathy due to ossification of the posterior longitudinal ligament: anterior decompression with spinal fusion versus laminoplasty. J Spinal Disord Tech 20:7-13, 2007

33. Matsunaga S, Sakou T: Ossification of the posterior longitudinal ligament of the cervical spine: etiology and natural history. Spine (Phila Pa 1976) 37:E309-E314, 2012

34. Matsunaga S, Sakou T, Taketomi E, Komiya S: Clinical course of patients with ossification of the posterior longitudinal ligament: a minimum 10-year cohort study. J Neurosurg 100 (3 Suppl Spine):245-248, 2004 
35. Matsunaga S, Sakou T, Taketomi E, Yamaguchi M, Okano T: The natural course of myelopathy caused by ossification of the posterior longitudinal ligament in the cervical spine. Clin Orthop Relat Res (305):168-177, 1994

36. Matsuoka T, Yamaura I, Kurosa Y, Nakai O, Shindo S, Shinomiya K: Long-term results of the anterior floating method for cervical myelopathy caused by ossification of the posterior longitudinal ligament. Spine (Phila Pa 1976) 26:241-248, 2001

37. McAfee PC, Regan JJ, Bohlman HH: Cervical cord compression from ossification of the posterior longitudinal ligament in non-orientals. J Bone Joint Surg Br 69:569-575, 1987

38. Mizuno J, Nakagawa H: Outcome analysis of anterior decompressive surgery and fusion for cervical ossification of the posterior longitudinal ligament: report of 107 cases and review of the literature. Neurosurg Focus 10(4):E6, 2001

39. Mizuno J, Nakagawa H, Matsuo N, Song J: Dural ossification associated with cervical ossification of the posterior longitudinal ligament: frequency of dural ossification and comparison of neuroimaging modalities in ability to identify the disease. J Neurosurg Spine 2:425-430, 2005

40. Mochizuki M, Aiba A, Hashimoto M, Fujiyoshi T, Yamazaki M: Cervical myelopathy in patients with ossification of the posterior longitudinal ligament. J Neurosurg Spine 10:122128,2009

41. Moher D, Liberati A, Tetzlaff J, Altman DG: Preferred reporting items for systematic reviews and meta-analyses: the PRISMA statement. PLoS Med 6:e1000097, 2009

42. Neyeloff JL, Fuchs SC, Moreira LB: Meta-analyses and forest plots using a Microsoft Excel spreadsheet: step-by-step guide focusing on descriptive data analysis. BMC Res Notes 5:52, 2012

43. Odate S, Shikata J, Kimura H, Yamamura S: Anterior corpectomy with fusion in combination with an anterior cervical plate in the management of ossification of the posterior longitudinal ligament. J Spinal Disord Tech 25:133-137, 2012

44. Ogawa Y, Toyama Y, Chiba K, Matsumoto M, Nakamura M, Takaishi H, et al: Long-term results of expansive open-door laminoplasty for ossification of the posterior longitudinal ligament of the cervical spine. J Neurosurg Spine 1:168 174,2004

45. Onari K, Akiyama N, Kondo S, Toguchi A, Mihara H, Tsuchiya T: Long-term follow-up results of anterior interbody fusion applied for cervical myelopathy due to ossification of the posterior longitudinal ligament. Spine (Phila Pa 1976) 26:488-493, 2001

46. Qizhi S, Xuelei W, Lili Y, Lei L, Linwei C, Yang L, et al: Segmental anterior decompression and fusion for multilevel ossification of the posterior longitudinal ligament. Orthopedics 35:e403-e408, 2012

47. Rubin CT, Hausman MR: The cellular basis of Wolff's law. Transduction of physical stimuli to skeletal adaptation. Rheum Dis Clin North Am 14:503-517, 1988

48. Sakai K, Okawa A, Takahashi M, Arai Y, Kawabata S, Enomoto M, et al: Five-year follow-up evaluation of surgical treatment for cervical myelopathy caused by ossification of the posterior longitudinal ligament: a prospective comparative study of anterior decompression and fusion with floating method versus laminoplasty. Spine (Phila Pa 1976) 37:367376, 2012

49. Saruhashi Y, Hukuda S, Katsuura A, Miyahara K, Asajima S, Omura K: A long-term follow-up study of cervical spondylotic myelopathy treated by "French window" laminoplasty. J Spinal Disord 12:99-101, 1999

50. Seichi A, Hoshino Y, Kimura A, Nakahara S, Watanabe M, Kato T, et al: Neurological complications of cervical lamino- plasty for patients with ossification of the posterior longitudinal ligament-a multi-institutional retrospective study. Spine (Phila Pa 1976) 36:E998-E1003, 2011

51. Suda K, Abumi K, Ito M, Shono Y, Kaneda K, Fujiya M: Local kyphosis reduces surgical outcomes of expansive opendoor laminoplasty for cervical spondylotic myelopathy. Spine (Phila Pa 1976) 28:1258-1262, 2003

52. Sugrue PA, McClendon J Jr, Halpin RJ, Liu JC, Koski TR, Ganju A: Surgical management of cervical ossification of the posterior longitudinal ligament: natural history and the role of surgical decompression and stabilization. Neurosurg Focus 30(3):E3, 2011

53. Takatsu T, Ishida Y, Suzuki K, Inoue H: Radiological study of cervical ossification of the posterior longitudinal ligament. J Spinal Disord 12:271-273, 1999

54. Tsukimoto H: A case report-autopsy of syndrome of compression of the spinal cord owing to ossification with spinal canal of cervical spine. Arch Jap Clin 29:1003-1007, 1960

55. Wang X, Chen D, Yuan W, Zhang Y, Xiao J, Zhao J: Anterior surgery in selective patients with massive ossification of posterior longitudinal ligament of cervical spine: technical note. Eur Spine J 21:314-321, 2012

56. Yamaura I, Kurosa Y, Matuoka T, Shindo S: Anterior floating method for cervical myelopathy caused by ossification of the posterior longitudinal ligament. Clin Orthop Relat Res (359):27-34, 1999

57. Yamazaki A, Homma T, Uchiyama S, Katsumi Y, Okumura $\mathrm{H}$ : Morphologic limitations of posterior decompression by midsagittal splitting method for myelopathy caused by ossification of the posterior longitudinal ligament in the cervical spine. Spine (Phila Pa 1976) 24:32-34, 1999

58. Yang SC, Yu SW, Tu YK, Niu CC, Chen LH, Chen WJ: Open-door laminoplasty with suture anchor fixation for cervical myelopathy in ossification of the posterior longitudinal ligament. J Spinal Disord Tech 20:492-498, 2007

59. Yuan W, Zhu Y, Liu X, Zhu H, Zhou X, Zhou R, et al: Postoperative three-dimensional cervical range of motion and neurological outcomes in patients with cervical ossification of the posterior longitudinal ligament: Cervical laminoplasty versus laminectomy with fusion. Clin Neurol Neurosurg 134:17-23, 2015

60. Zhao X, Xue Y, Pan F, Zhao H, Li P, Wang P, et al: Extensive laminectomy for the treatment of ossification of the posterior longitudinal ligament in the cervical spine. Arch Orthop Trauma Surg 132:203-209, 2012

\section{Disclosures}

The authors report no conflict of interest concerning the materials or methods used in this study or the findings specified in this paper.

\section{Author Contributions}

Conception and design: Steinmetz, Alentado, Mroz, Benzel. Acquisition of data: Mehdi. Analysis and interpretation of data: Mehdi. Drafting the article: Mehdi. Critically revising the article: all authors. Reviewed submitted version of manuscript: all authors. Statistical analysis: Mehdi. Study supervision: Steinmetz, Alentado, Benzel.

\section{Correspondence}

Michael P. Steinmetz, Department of Neurological Surgery, Center for Spine Health, The Cleveland Clinic, 9500 Euclid Ave., S-40, Cleveland, OH 44195. email: steinmm@ccf.org. 